\title{
From Aspirin to Aspirin Resistance - History, Biochemical Background, Diagnostics and Clinical Relevance
}

\author{
Götz Nowak \\ Research Unit 'Pharmacological Haemostaseology', Medical Center, Friedrich Schiller University Jena, Germany
}

\section{Key Words}

ASA - Aspirin · Aspirin resistance - Platelets · COX-1 .

Platelet function test

\section{Summary}

The story of success of aspirin has lasted for more than 100 years. Initially used as an analgetic with anti-inflammatory, antirheumatic as well as antipyretic effects, aspirin has been widely used as antithrombotic drug since the 1970s, too, due to its more recently discovered platelet inhibitory efficacy. Primary and secondary prophylaxis of cardiovascular events by long-term intake of aspirin has been performed million-fold worldwide, even without any medical attendance. In spite of a clear positive effect on the incidence of coagulation disorders, a residual risk remains for the aspirin user - the aspirin resistance. In this review a short historical survey is given, and the biochemical background of the aspirin effect on blood platelets as well as aspirin resistance with the possible causes and the clinical relevance are described. Different laboratory methods for detection of aspirin resistance are discussed with respect to validity and limitations. Not until both the predisposition for aspirin resistance and the presence of acute aspirin resistance can be clearly detected using reliable methods, the patient will receive adequate treatment.

\section{Introduction}

After the New York Times had reported in summer of 2004 that up to $40 \%$ of the aspirin users in the USA showed no effect of aspirin, the term aspirin resistance has become very

\begin{tabular}{ll}
\hline KARGER & ( 2007 S. Karger GmbH, Freiburg \\
Fax +497614520714 & Accessible online at: \\
$\begin{array}{l}\text { E-mail Information@Karger.de } \\
\text { www.karger.com }\end{array}$ & www.karger.com/tmh
\end{tabular}

popular in the USA [1]. Bringing into mind that about 15,000 tons of aspirin are produced per year in the USA, one can imagine that from the 30-40 million people who take this drug daily, only a minority of the users actually benefit from the

\author{
Schlüsselwörter \\ ASS · Aspirin · Aspirinresistenz · Blutplättchen · COX-1 . \\ Thrombozytenfunktionstest
}

\section{Zusammenfassung}

Die Erfolgsstory des Aspirins währt bereits mehr als 100 Jahre. Zunächst als Schmerzmittel mit entzündungshemmenden, antirheumatischen und fiebersenkenden Wirkkomponenten eingesetzt, wird Aspirin seit den 1970er Jahren aufgrund seiner neu entdeckten plättchenfunktionshemmenden Wirkung auch als Antihrombotikum breit angewendet. Die Primär- und Sekundärprävention kardiovaskulärer Ereignisse durch langjährige Einnahme von Aspirin wird weltweit millionenfach, auch ohne ärztliche Überwachung, durchgeführt. Trotz eindeutig positivem Effekt auf die Prävalenz von Gerinnungskrankheiten bleibt ein Restrisiko für den Aspirintherapierten, die Aspirinresistenz. In dieser Übersicht wird ein kurzer geschichtlicher Überblick gegeben und die biochemischen Grundlagen der Aspirinwirkung auf die Thrombozyten dargestellt. Die möglichen Ursachen der Aspirinresistenz und ihre klinische Relevanz werden beschrieben. Verschiedene Methoden zur Diagnostik einer Aspirinresistenz werden hinsichtlich ihrer Aussagefähigkeit und Grenzen kritisch betrachtet. Erst wenn es gelingt, sowohl die Prädisposition für eine Aspirinresistenz als auch eine akute Aspirinresistenz sicher zu erkennen, kann dem betroffenen Patienten effektiv geholfen werden.

Götz Nowak, MD

Research Unit 'Pharmacological Haemostaseology'

Medical Center, Friedrich Schiller University Jena

Drackendorfer Straße 1, 07747 Jena, Germany

Tel. +49 3641 93257-01, Fax -02

E-mail AGPHH@med.uni-jena de 
known and widely accepted effect of aspirin, i.e. the prevention of coagulation disorders when taken in lower doses.

In the current controversial debate about the feasibilities to detect aspirin resistance in patients, there is a number of problems that are insufficiently solved or not solved at all by now. The large interventional studies of the 1980s and 1990s have finally only partially led to a success, namely the prevention of vascular events or acute cardiac events or stroke. In metaanalyses, it was shown that only $25-27 \%$ of the patients had a benefit from daily aspirin intake [2]. On the other hand, a number of side-effects that may lead to severe malfunctions, even to death, is of considerable medical interest [3-8].

In this review a short historical survey is given, and the biochemical background of the aspirin effect on blood platelets as well as the presence of aspirin resistance with its possible causes and clinical relevance are described. Different laboratory methods for detection of aspirin resistance are mentioned and discussed concerning validity and limitations.

\section{Aspirin History}

110 years ago, in the pharmacological laboratories of the Bayer company in Wuppertal-Elberfeld, the chemist Hoffmann succeeded for the first time in producing pure acetylsalicylic acid (ASA); the participation of A. Eichengrün is still being discussed [9]. The main aim was a better solubility of salicylic acid which had been introduced into clinical therapy of rheumatic diseases 20 years ago. Initial studies have confirmed the assumption that the salicylic acid is the actual active agent [10]. Since the turn to the 20th century ASA (aspirin) has been widely used as analgesic, anti-inflammatory, antirheumatic, and antipyretic drug. Nearly 50 years later first reports were published that ASA may lead to a bleeding tendency [11]. Due to the then very high doses of ASA and other non-steroidal antirheumatic drugs, it has been assumed that this effect would be based on an interference with prothrombin synthesis, leading to bleeding which results from prothrombin deficiency [12]. In the 1960s first investigations of the platelet inhibitory effect of ASA were published, and daily doses have been recommended which were far below the by then usually prescribed doses for antirheumatic therapy [13]. In 1971 Vane [14] identified the prostaglandin synthesis as the central target of ASA. In the following years the platelet receptor and the real molecular mode of action of ASA, i.e. the irreversible acetylation of serine 530 in the cyclooxygenase, have been discovered $[15,16]$. By means of the acetate group in the serine side chain a steric hindrance of the natural substrate of cyclooxygenase, the arachidonic acid (AA), results. The acetylation of cyclooxygenase is irreversible and the ensuing induced inhibition of platelet function occurs only after elimination of overaged malfunctioning platelets from circulation. By acetylation of the hydroxyl group in the O-position of salicylic acid, ASA is able to transfer this acetate group to pro- teins using a number of unspecific esterases. Furthermore, interactions with proteins in the platelet membrane, the plasma and the inner platelet take place. ASA has a better but still low solubility compared to salicylic acid. Solubility of ASA depends on the $\mathrm{pH}$, and enhances with increasing $\mathrm{pH}$. After the side-effects of ASA became known, mostly micro-bleedings in the upper gastrointestinal tract, pharmaceutical formulations of ASA have been developed that allow a delayed release of ASA from e.g. enteric coated formulations or ASA crystal coated formulations. Thereby, the local mucosa damaging effect of ASA may be prevented. Meanwhile there are at least 50 different ASA formulations, e.g. slow release formulations that find their target enzyme in platelets already presystemically in the enteral blood circulation [17]. Of a usual ASA dose between 100 and $350 \mathrm{mg}$, about $50 \%$ of ASA are already presystemically deacetylated. The other half of ASA enter the systemic blood circulation and fast become deacetylated by esterases and also by interactions with platelets and other cells.

\section{Aspirin and Platelets}

When the endothelial wall of blood vessels is damaged or in case of an atherosclerotic plaque collagen is exposed, circulating platelets may adhere to the subendothelial matrix. This is mediated by von Willebrand factor (vWF) at which FVIII locally accumulates. vWF makes use of several glycoproteins depending on shear stress intensity, either GP Ia/IIa or GP Ib/V/IX [18]. These vWF receptors at the platelet surface cause platelet adhesion and platelet activation. With continuous platelet spreading, shape change and release of platelet vesicles with procoagulant material, the local coagulation process is induced. Of great importance is the release of bound calcium from special calcium depots. This cytosolic $\mathrm{Ca}^{2+}$ is necessary for the structural change of the fibrinogen receptor (GP IIb/IIIa) at the platelet surface. Thereby it becomes able to use circulating fibrinogen as adhesive protein for platelet-platelet binding. Furthermore, a number of procoagulant molecules are released from platelet granules, e.g. ADP that stimulates ADP receptors of the platelet membrane and causes further platelet activation [19]. Of special importance are the changes of the fluid phase of platelet membrane where the polyunsaturated fatty acids composed of $20 \mathrm{C}$ atoms, which are present in resting platelets, are replaced by polysaturated 'stable' fatty acids [20].

When platelets are permanently activated (e.g. in atherosclerosis or diabetic vasculopathy), the platelet membranes becomes depleted of AA, or not enough AA is provided by phospholipases. In consequence, platelets are not able to give an adequate physiologic answer to the stimulus of an aggregation agonist ('pseudo-resistance'). AA represents the main part of the unsaturated fatty acids released during platelet activation. It is released from the membrane environment and 
initiates the prostaglandin metabolism of platelets for which platelet specific enzymes are used. The central enzyme for processing AA is cyclooxygenase $1(\mathrm{COX}-1)$ of the platelet which synthesizes thromboxane A2 ( $\left.\mathrm{TXA}_{2}\right)$ from AA using thromboxane synthase [21]. TXA 2 is the main metabolic activator of platelet aggregation and can support the further recruitment of platelets to the micro white clots. $\mathrm{TXA}_{2}$ enhances the activation of fibrinogen receptors at the platelet membrane and interacts with granule contents released by the activated platelets. Furthermore, $\mathrm{TXA}_{2}$ is a potent vasoconstrictor. In this activation process, ASA affects the pilot enzyme COX-1 by irreversible acetylation, thus decreasing the $\mathrm{TXA}_{2}$ formation of the platelets [22]. The permanent irreversible inhibition of COX-1 stops the further enzymatic activity of platelets via COX-1. In the blood, $\mathrm{TXA}_{2}$ is converted into its stable metabolite $\mathrm{TXB}_{2}$ and is eliminated via the kidneys [23].

\section{Aspirin Resistance}

Aspirin resistance occurs in two forms - as laboratory resistance and clinical resistance. Whereas laboratory aspirin resistance is defined as the failure of aspirin to inhibit platelet $\mathrm{TXA}_{2}$ formation or inhibit platelet function tests that depend on platelet $\mathrm{TXA}_{2}$ production (e.g. platelet aggregation), clinical aspirin resistance is defined as the failure of aspirin to prevent clinical atherothromboembolic ischaemic events in patients under aspirin treatment [24]. However, this problem is more accurately referred to as aspirin treatment failure [25].

\section{Laboratory Diagnosis of Aspirin Resistance}

Besides measurement of the $\mathrm{TXB}_{2}$ level, aspirin resistance is mainly diagnosed by measurement of platelet function, either in platelet rich plasma (PRP) or in whole blood. Measurement principles are light transmission or electrical impedance. In addition to the classical Born method (platelet aggregometry in PRP) and electrical impedance measurement, further methods are available or still under development, including PFA$100^{\circledR}$, VerifyNow ${ }^{\circledR}$ Aspirin (formerly RPFA), Plateletworks ${ }^{\circledR}$, PlaCor-PRT, ThromboGuide, and Impact (Cone and Plate Analyzer) (table 1). In the following, the essential methods used in clinical practice will be discussed.

\section{Measurement of $\mathrm{TXB}_{2}$ Level in Serum or Urine}

By biochemical analytical methods the TXA 2 level can be directly measured in serum in the form of the stable metabolite $\mathrm{TXB}_{2}$. A reduced $\mathrm{TXB}_{2}$ level in serum always indicates an inhibitory effect on COX-1 that arises from irreversible inhibition by ASA. However, this mechanism is not platelet specific; also other cells and tissues can contribute to a reduced $\mathrm{TXA}_{2}$ serum level and may falsely indicate an ASA resistance. Fur- thermore, this method is laborious and requires much knowhow. Another possibility is to measure the 11-dehydro- $\mathrm{TXB}_{2}$ level in urine. This 11-dehydro $\mathrm{TXB}_{2}$ level is directly proportional to the serum $\mathrm{TXB}_{2}$ level and therefore also indicates a decreased COX-1 activity of the platelets. This parameter is not platelet specific but correlates well with clinical events [26]. However, until now there are no comprehensive results of aspirin resistance studies using this test.

\section{Measurement of Platelet Function by Optical Aggregometry}

By optical aggregometry the light transmission through a platelet suspension is measured. By addition of an agonist (e.g. ADP, collagen), platelet aggregation is induced and due to formation of aggregates light transmission increases. Optical aggregometry represents the most widely used platelet function test and is the gold standard for measuring aspirin resistance. Aspirin resistance in this test is defined as follows: After inducing platelet aggregation by $10 \mu \mathrm{mol} / \mathrm{l}$ ADP, the platelet aggregation is still greater than $70 \%$. When AA is used as agonist $(0.5 \mathrm{mg} / \mathrm{ml})$, an aggregation of more than $20 \%$ indicates aspirin resistance [27].

\section{Measurement of Platelet Function by Impedance \\ Aggregometry}

This method resembles optical aggregometry, i.e. platelet aggregation is induced by aggregation agonists. Between two electrodes the change of electrical impedance is measured depending on formation of platelet aggregates. The advantage of impedance aggregometry is that whole blood can be used, and thereby the preparation of PRP is not required.

\section{$P F A-100^{\circledR}$}

In PFA-100 (Dade-Behring, Marburg, Germany) citrated whole blood is used, which is characterised by a variety of individual variations in platelet count, platelet function, number of other blood cells as well as content of plasmatic platelet sensitive factors (prothrombin, vWF, FXIII, FVIII, FV and others), all of which may influence the results. In PFA-100 blood is aspired into a capillary that is coated with aggregation agonists. Due to the interaction of platelets with the cartridge wall fixed agonists, a closure of the capillary results. The closure time for different agonists is given as result and is used as a measure of platelet function. Normal closure time for collagen-epinephrine coated cartridges is 190 s. For aspirin responders this closure time is significantly prolonged. A shortened or normal closure time for patients on ASA is assessed as aspirin resistance. Data to aspirin resistant patients detected by PFA-100 vary between 9.5 and $40 \%$ (28). When results of PFA-100 were compared with results of AA induced and ADP induced platelet aggregation in PRP, no consistent findings to aspirin resistance could be shown [29]. A possible cause might be that both methods detect different classes of aspirin resistant patients. 


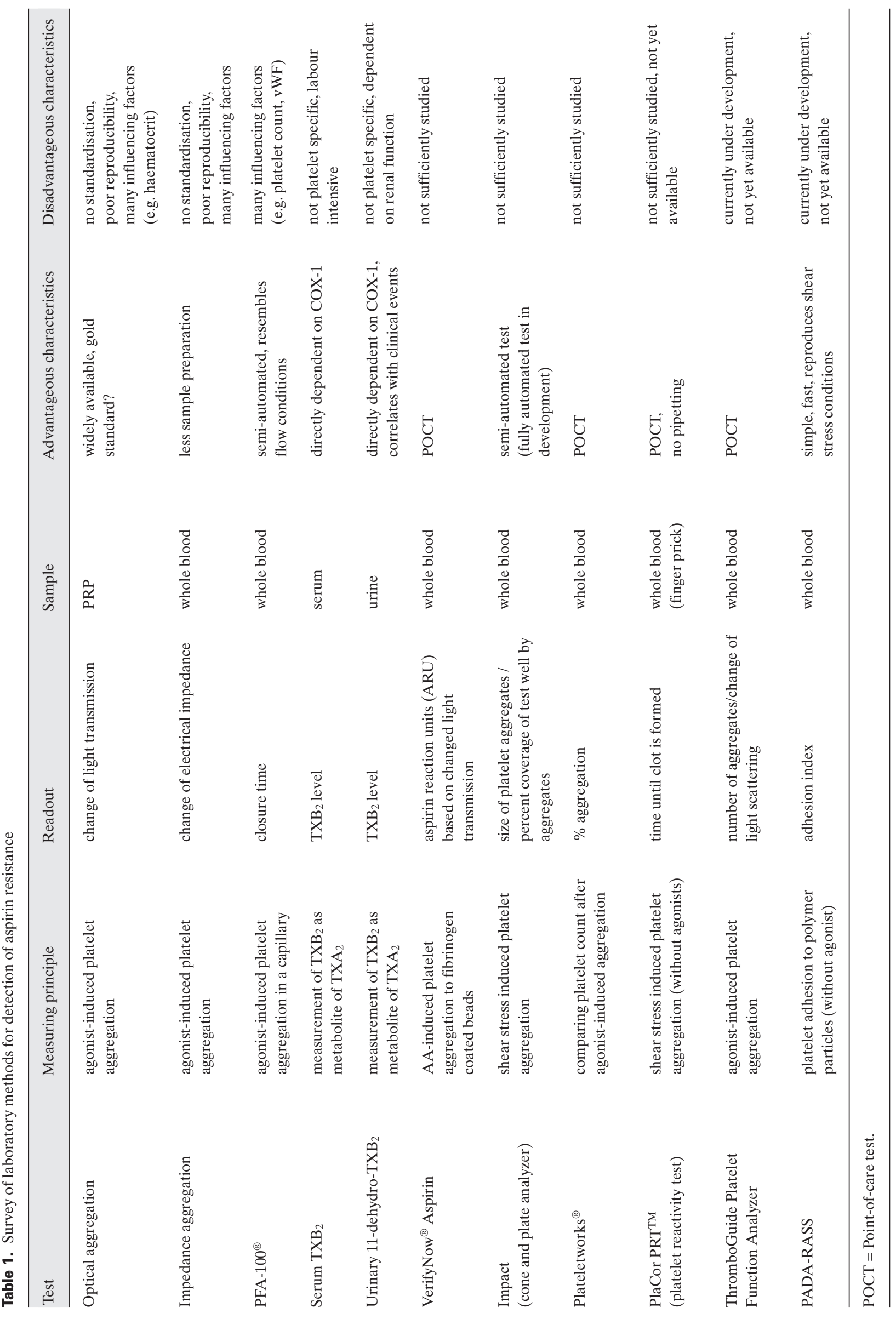


VerifyNow ${ }^{\circledR}$ Aspirin

In VerifyNow Aspirin (Accumetrics, San Diego, CA, USA) (formerly Ultegra RPFA-ASA) the AA induced platelet aggregation to fibrinogen coated beads is optically measured in diluted whole blood. The result is expressed as aspirin response units (ARU), and a reading of more than 550 ARU indicates aspirin resistance. Neither results of aspirin resistance measurement using the present VerifyNow Aspirin nor those of the former similar system RPFA do agree with other detection methods [30]. It is still unclear whether even low dose aspirin users can be tested for aspirin resistance.

\section{Other Methods}

Other methods such as PlaCor PRT, ThromboGuide, Plateletworks are not yet available but currently under development or approval, and no clinical studies involving a sufficient patient number have been performed by now. The latter also applies to Impact (Cone and Plate Analyzer) (Impact-R ${ }^{\circledR}$; DiaMed, Cressier s/Morat, Switzerland).

In our laboratories, own experience of aspirin resistance detection is existent using a modification of the Platelet Adhesion Assay (PADA) [31]. The test named PADA-RASS can be used even for screening of patients who do not take aspirin. For PADA-RASS heparinised whole blood is used. In the numerous investigations performed by now in patients and healthy volunteers a relatively high incidence of aspirin resistance has been shown. The identification of a familial accumulation of aspirin resistance provides first confirmatory data for the presumption that a genetic predisposition for aspirin resistance exists [32-35]. For this purpose, genetic investigations will be performed soon. Advantage of PADA-RASS consists in only moderate technical equipment and a short measuring time until reliable results are obtained.

\section{Limitations or Pitfalls of the Laboratory Diagnosis of Aspirin Resistance}

\section{$\mathrm{TXA}_{2}$ Synthesis}

Besides $\mathrm{TXA}_{2}$ synthesis in platelets, $\mathrm{TXA}_{2}$ is also produced in monocytes and macrophages that accumulate in atherosclerotic plaques [36]. In these cells, COX-2 converts AA to the pro-inflammatory prostaglandins $\mathrm{G} 2 / \mathrm{H} 2$. These prostaglandins are either transformed to $\mathrm{TXA}_{2}$ by the thromboxane synthase of the monocytes and macrophages, or they are released. The prostaglandins $\mathrm{G} 2 / \mathrm{H} 2$ can also be taken up by platelets and are transformed to $\mathrm{TXA}_{2}$ by thromboxane synthase [37]. This represents an alternative transcellular pathway by which a platelet aggregation can be induced in spite of aspirinblocked COX-1 in platelets. Aspirin does not influence thromboxane synthase activity, and COX-2 is influenced only at higher ASA concentrations in platelets and pro-inflammatory mediator cells. During an elevated platelet turnover, platelets are released that have a significantly decreased biologic half life and increased COX-2 content [38]. These platelets use COX-2 as aspirin resistant AA-TXA 2 pathway and represent a possible explanation for aspirin resistance in critical care situations [39].

Measurement of $\mathrm{TXB}_{2}$ in plasma or serum is not simple, and the methods are based on ELISA, EIA or radioimmunoassay. Specific investigations are gas chromatography and mass spectroscopy. Due to the fact that also COX-2 of blood cells and endothelial cells can form $\mathrm{TXA}_{2} / \mathrm{B}_{2}$, it becomes obvious that measurement of $\mathrm{TXB}_{2}$ in coagulation disorders with strong platelet activation is ineffective. This cellular non-specificity and lack of discriminatory power may lead to false qualitative or quantitative statements. The same applies to the measurement of urinary 11-dehydro $\mathrm{TXB}_{2}$.

The antiplatelet effect of aspirin that can be detected by several laboratory methods has an individual variation and is influenced by further non-blood derived factors such as the blood pressure or nicotine abuse [40, 41]. Obviously, also a reduced bioavailability of aspirin has a considerable influence on the $\mathrm{TXA}_{2} / \mathrm{B}_{2}$ level in blood and urine. Possible causes might be a non-compliance of the patient, resulting in an incorrect or lacking intake of aspirin, underdosed aspirin, reduced gastrointestinal adsorption or an increased extraplatelet metabolism of aspirin [42, 43]. Recently great importance was attached to the finding that non-steroidal anti-inflammatory drugs (NSAID; e.g. indometacin, ibuprofen) reversibly and competitively inhibit the COX-1 receptor [44, 45]. By substrate competition at COX-1, AA might displace NSAID and thus imitate aspirin resistance. Due to the shortterm availability of native ASA in the presystemic and the systemic circulation following singular ASA intake per day, these mechanisms certainly are of importance for drug induced aspirin resistance.

Furthermore, alternative platelet activation pathways that are not aspirin sensitive might play a role. Such activation pathways comprise the elevated release of ADP during haemolytic reactions, thrombin occupation of protease activated receptors (PARs) that induce direct platelet activation and aggregation, or the presence of adrenalin in the circulation ('potentiating reaction'). Moreover, from interactions between microparticle bearing red blood cells and platelets a direct activation via PARs might occur. In states of enhanced coagulation activation, e.g. disseminated intravascular coagulation (DIC) or sepsis, a highly increased production of platelets is induced in megakaryocytes, resulting in a permanent release of very 'young' platelets into the circulation simulating aspirin resistance.

\section{The Right Anticoagulant}

All in vitro or ex vivo platelet function tests are performed solely in citrated whole blood or citrated PRP obtained thereof. At this point the question ensues whether in vivo conditions can be adequately represented in vitro using citrated blood. The removal of $\mathrm{Ca}^{2+}$ by citrate results in a depletion of 
free calcium at the outside of the platelet membranes that in turn influences intracellular calcium depots. In a pilot publication [46] it was demonstrated that whole blood anticoagulated with r-hirudin shows a different platelet aggregation compared to citrated blood. In parallel determinations of platelet aggregation using citrated or hirudinised whole blood, as well as PRP obtained thereof, the involvement of extracellular free calcium in platelet function has been shown. At physiologic $\mathrm{Ca}^{2+}$ concentrations during platelet aggregation significantly less $\mathrm{TXA}_{2}$ is formed. Furthermore it is known that several platelet receptors are $\mathrm{Ca}^{2+}$ dependent. Although results of platelet aggregation in citrated and hirudinised blood having different $\mathrm{Ca}^{2+}$ concentrations are comparable, they do not reflect the real pathophysiologic reaction of platelets in vivo.

\section{Other Limitations}

Limitations of detecting aspirin resistance in PRP using aggregation agonists (such as AA, collagen, ADP, thrombin, epinephrine) consist mainly in the involvement of different activation pathways since besides the TX pathway other platelet glycoprotein receptors are also involved. Further limitations of aggregometry based on optical transmission or electrical impedance are given by the measurement devices used (e.g. stirring speed, sample volume, experience of the performing person) and by patient specific parameters (e.g. age, body weight, haematocrit, platelet count).

Since for these tests no international standardisation exists, the results of different laboratories show great variations. Therefore a consensus is being sought, at least for the application of AA and other agonists. For the detection of aspirin resistance most frequently $1 \mathrm{mmol} / \mathrm{l} \mathrm{AA}$ or $1 \mu \mathrm{g} / \mathrm{ml}$ collagen are used as agonists. It is still in dispute whether the platelet number in PRP influences the measurement. Another open question is whether the number of specific cell receptors at the platelet surface that can vary considerably depending on individual medical situation and that is dynamically controlled by the platelets has an effect on the test result.

\section{Clinical Relevance of Aspirin Resistance}

In 1993 Grotemeyer et al. [47] published a 2-year follow up of aspirin responders and non-responders. In this study 180 patients were involved. $33 \%$ of the stroke patients had developed an aspirin resistance (measured using the Grotemeyer assay). At the follow-up examination after 2 years, $40 \%$ of the aspirin resistant patients were affected by severe vascular events as compared to only $5 \%$ of those patients who did not have an aspirin resistance. Also the HOPE study [26] confirmed the protective effect of aspirin since, among the 976 high-risk patients which were treated with different aspirin doses, after 4.5 years those patients had the less occurrence of severe vascular diseases or death due to vascular events that had the less urinary 11-dehydro $\mathrm{TXB}_{2}$ level. There was a linear correlation between increasing urinary 11-dehydro $\mathrm{TXB}_{2}$ level and incidence of severe vascular events. From this study it was concluded that aspirin resistance was not acquired during a vascular event but has existed before.

Aspirin resistance is associated with an increasing risk of vascular events. In coincidence with further thrombophilic risk factors or high blood pressure and increased blood cholesterol level, the risk of an acute coagulation disorder continues to potentiate. Similar results were obtained in a study by Gum et al. [48] in 2003, who treated 326 patients with coronary or cerebrovascular events with $325 \mathrm{mg} /$ day aspirin. Follow-up time was 2 years. Prove of aspirin resistance was done using aggregometry in PRP with ADP or AA as agonist. From those patients who were classified as aspirin resistant according to the study criteria, $29 \%$ had a severe vascular event within 2 years, compared with $10 \%$ in the group of non-aspirin resistant patients.

It would be of central importance to prognostically detect a predisposition for aspirin resistance to exclude these individuals from long-term aspirin intake. By this also a thrombophilic risk factor might be eliminated in case of a paradox reaction to ASA that we have seen in several patients using PADARASS. In these patients ASA caused platelet activation instead of inhibition. Based on today's knowledge, it is certain that besides a genetically defined aspirin resistance there are also induced forms, as discussed previously in this review. Data regarding the prevalence of aspirin resistance vary between 5 and $60 \%$. Drawbacks of the currently available aspirin resistance studies are a relatively small number of patients analysed and the use of different detection methods. Even when the same method was applied, different agonist concentrations, measuring times, sample volumes and platelet numbers in PRP were used, precluding direct comparisons. Furthermore it is still unclear which anticoagulant of blood or PRP has the least influence on the measuring result. Of special importance is the still unsettled specificity and sensibility of the methods. All methods available by now have only an insufficient concordance. Therefore it must be stated that we are just at the beginning with respect to our knowledge on aspirin resistance. The collaboration between specialists for laboratory medicine, clinicians and haemostaseologists is very essential for the progress in aspirin resistance diagnostics. 


\section{References}

1 Pollack A: For some, aspirin may not help hearts. New York Times July 20, 2004

2 Antithrombotic Trialist's Collaboration: Collaborative meta-analysis of randomised trials of antiplatelet therapy for prevention of death, myocardial infarction, and stroke in high risk patients. BMJ 2002;324:71-86.

3 Knapp HR, Sladek K, FitzGerald GA: Increased excretion of leukotriene E4 during aspirin-induced asthma. J Lab Clin Med 1992;119:48-51.

4 Zeitz HJ: Bronchial asthma, nasal polyps, and aspirin sensitivity - Samter's syndrome. Clin Chest Med 1988;9:567-576.

5 McGuigan MA: A two-year review of salicylate deaths in Ontario. Arch Intern Med 1987;147:510512.

6 Iobst WF, Bridges CR, Regan-Smith MG: Antirheumatic agents: CNS toxicity and its avoidance. Geriatrics 1989;44:95-100,102.

7 Gladtke E, Schauseil-Zipf U: Reye's syndrome. Monatsschr Kinderheilk 1987;135:699-704.

$>8$ Schwarz A: Analgesic associated nephropathy. Klin Wochenschr 1987;65:1-16.

9 Sneader W: The discovery of aspirin: a reappraisal BMJ 2000;321:1591-1594.

10 Withauer K: Aspirin, ein neues Salicylpräparat. Heilkunde 1899:3:396.

11 Singer R: Acetylsalicylic acid, probable cause for secondary post-tonsillectomy hemorrhage. Preliminary report. Arch Otolaryng 1945;42:19.

12 Wising P: Haematuria, hypoprothrombinemia and salicylate medication. Acta Med Scand 1952;141:256.

13 O'Brien JR: Effects of salicylates on human platelets. Lancet 1968;i:779-783.

14 Vane JR: Inhibition of prostaglandin biosynthesis as a mechanism of action of aspirin-like drugs. Nat New Biol 1971;231:232-235.

15 DeWitt DL, El-Harith EA, Kraemer SA, Andrews MJ, Yao EF, Armstrong RL, Smith WL: The aspirin- and heme-binding sites of ovine and murine prostaglandin endoperoxide synthases. J Biol Chem 1990:265:5192-5198.

-16 Funk CD, Funk LB, Kennedy ME, Pong AS, FitzGerald GA: Human platelet/erythroleukemia cell prostaglandin G/H synthase: CDNA cloning, expression, mutagenesis and gene chromosomal assignment. FASEB J 1991;5:2304-2312.

17 Vial JH, McLeod LJ, Roberts MS, Seville PR: Selective inhibition of platelet cyclooxygenase with controlled release, low-dose aspirin. Aust N Z J Med 1990;20:652-656.

18 Roth GJ, Calverley DC: Aspirin, platelets and thrombosis: theory and practice. Blood 1994;83: 885-898.

19 McNicol A, Israels SJ: Platelets and anti-platelet therapy. J Pharmacol Sci 2003;93:381-396.

20 Maclouf J, Folco G, Patrono C: Eicosanoids and iso-eicosanoids: constitutive, inducible and transcellular biosynthesis in vascular disease. Thromb Haemost 1998;79:691-705.
21 Roth GJ, Majerus PW: The mechanisms of the effect of aspirin on human platelets. J Clin Invest 1975;56:624-632.

22 Burch JW, Standfort N, Majerus PW: Inhibition of platelet prostaglandin synthetase by oral aspirin. J Clin Invest 1978;61:314-319.

23 Fitzgerald GA, Oates JA, Hawiger J, Maas RL, Roberts LJ 2nd, Lawson JA, Brash AR: Endogenous biosynthesis of prostacycline and thromboxane and platelet function during chronic administration of aspirin in man. J Clin Invest 1983;71:676688.

24 Bhatt D, Topol EJ: Scientific and therapeutic advances in antiplatelet therapy. Nature 2003;2:15-28.

25 Hankey GJ, Eikelboom JW: Aspirin resistance. Lancet 2006;367:606-617.

26 Eikelboom JW, Hirsh J, White JI, Hohnson M, Yi Q, Yussuf S: Aspirin resistant thromboxane biosynthesis and the risk of myocardial infarction, stroke or cardiovascular death in patients at risk of high for cardiovascular event. Circulation 2002;105: 1650-1655.

27 Mueller MR, Salat A, Stangl P, Murabito M, Pulaki S, Boehm D, Koppensteiner R, Ergun E, Mittlboeck M, Schreiner W, Losert U, Wolner E: Variable platelet response to low-dose ASA and the risk of limb deterioration in patients submitted to peripheral arterial angioplasty. Thromb Haemost 1997;78:1003-1007.

28 Feuring M, Schultz A, Losel R, Wehling M: Monitoring acetylsalicylic acid effects with the platelet function analyzer PFA-100. Semin Thromb Hemost 2005;31:411-415.

29 Gum PA, Kottke-Marchant K, Poggio ED, Gurm H, Welsh PA, Brooks L, Sapp SK, Topol EJ: Profile and prevalence of aspirin resistance in patients with cardiovascular disease. Am J Cardiol 2001;88:230235.

30 Wheeler GL, Braden GA, Steinhubl SR, Kereiakes DJ, Kottke-Marchant K, Michelson AD, Furman MI, Mueller MN, Moliterno DJ, Sane DC: The Ultegra rapid platelet function assay: comparison to standard platelet function assays in patients undergoing percutaneous coronary intervention with abciximab therapy. Am Heart J 2002;143:602-611.

31 Nowak G, Wiesenburg A, Schumann A, Bucha E: Platelet adhesion assay - a new quantitative whole blood test to measure platelet function. Thromb Hemost 2005:31:470-475.

32 Goodman, T, Sharma P, Ferro A: The genetics of aspirin resistance. Int J Clin Pract 2007;61:826-834.

33 Halushka M, Walker LP, Haushaka PV: Genetic variation in cyclo-oxygenase 1. Effects on response to aspirin. Clin Pharmacol Ther 2003;73:122-130.

34 Cambria-Kiely JA, Gandhi PJ: Aspirin resistance and genetic polymorphism. J Thromb Thrombolysis 2002:14:51-58
35 Jefferson BK, Foster JH, McCarthy JJ, Ginsburg G, Parker A, Kottke-Marchant K, Topol EJ: Aspirin resistance and a single gene. Am J Cardiol 2005;96: 805-808.

36 Schonbeck U, Sukhova GK, Graber P, Coulter S, Libby P: Augmented expression of cyclooxygenase2 in human atherosclerotic lesions. Am J Pathol 1999;155:1281-1291.

37 Karim S, Habib A, Levy-Toledano S, Maclouf J: Cyclooccygenase- 1 and- 2 of endothelial cells utilize exogenous or endogenous arachidonic acid for transcellular production of thromboxane. J Biol Chem 1996;271:12042-12048.

38 Rocca B, Secchiero P, Ciabattoni G, Ranelletti FO, Catani L, Guidotti L, Melloni E, Maggiano N, Zauli G, Patrono C: Cyclooxygenase-2 expression is induced during human megakaryopoiesis and characterizes newly formed platelets. Proc Nat Acad Sci U S A 2002;99:7634-7639.

39 Weber AA, Zimmermann KC, Meyer-Kirchrath J, Schrör K: Cyclooxygenase-2 in human platelets as a possible factor in aspirin resistance. Lancet 1999; 353:900.

40 Hung J, Lam JY, Lacoste L, Letchacovyki G: Cigarette smoking acutely increases platelet thrombus formation in patients with cornary artery disease taking aspirin. Circulation 1995;92:2432-2436.

41 Weber AA, Liesener S, Schanz A, Hohlfeld T, Schrör K: Habitual smoking causes an abnormality in platelet thromboxane A2 metabolism and results in an altered susceptibility to aspirin effects. Platelets 2000;11:177-182.

42 Needs CJ, Brooks PM: Clinical pharmacokinetics of the salicylates. Clin Pharmacokinet 1985;10:164 177.

43 Williams FM: Clinical significance of esterases in man. Clin Pharmacokinet 1985:10:392-403.

44 MacDonald TM, Wei L: Effect of ibuprofen on cardioprotective effect of aspirin. Lancet 2003;361: 573-574.

45 Curtis JP, Krumholz HM: The case for an adverse interaction between aspirin and non-steroidal antiinflammatory drugs. Is it time to believe the hype? J Am Coll Cardiol 2004;43:991-993.

46 Bretschneider E, Glusa E, Schrör K: ADP-, PAFand adrenaline-induced platelet aggregation and thromboxane formation are not affected by thromboxane antagonist at physiological external $\mathrm{Ca}++$ concentrations. Thromb Res 1994;75:233-242.

47 Grotemeyer KH, Scharafinski HW, Husstedt IW: Two-year follow-up of aspirin responder and aspirin nonresponder: a pilot-study including 180 post-stroke patients. Thromb Res 1993;71:397-403.

48 Gum PA, Kottke-Marchant K, Welsh PA, White J, Topol EJ: A prospective, blinded determination of the natural hitory of aspirin resistane among stable patients with cardiovascular disease. J Am Coll Cardiol 2003;41:961-965. 